Original Article

\title{
"ROLE OF COMPUTED TOMOGRAPHY BRAIN IN ESTABLISHING THE FREQUENCY OF DIFFERENT TYPES AND SUBTYPES OF STROKE AND TO CORRELATE THEM WITH RISK FACTORS AND TIME OF ONSET OF SYMPTOMS AND OUTCOME"
}

\author{
Iram Javeed*' Nayab Alia**, Adeen Akram**** \\ *Senior Registrar, Madina Teaching Hospital University Medical and Dental College, Faisalabad. \\ ${ }^{* *}$ Associate Professor, Madina Teaching Hospital University Medical and Dental College, \\ Faisalabad. \\ $* * * *$ House Officer DHQ/Allied Hospital Faisalabad.
}

\section{ABSTRACT:}

Objectives: This study was performed to establish role of CT Brain in establishing frequency of different type and subtypes of stroke in Pakistani population and to correlate CT findings with risk factors and duration of onset of symptoms that lead patient to take admission in hospital and outcome of different types of stroke.

Methodology: A sample of hundred patients was taken from SOCIAL SECURITY HOSPITAL MULTAN ROAD LAHORE over a period of nine months starting from October 2014 to June 2015. A prospective study with convenient sampling technique was performed. Equipment used was 64 slice TOSHIBA CT scanner machine. Patients with incomplete data, pediatric age group to age 14 years, stroke due to trauma, infections or tumours were excluded from this study. A detailed questionnaire was used to collect data from the patients that included age, sex, type of stroke, time of onset of symptoms, location of lesion on CT brain, odema of cerebral tissues, midline shift predisposing risk factors like HTN, DM, oldage, high cholesterol levels, CLDetc and outcome of stroke and time of death in some cases was recorded.The collected data was analyzed by SPSS-20.

Results: Shows that infarctive stroke was more prevalent type of stroke in Pakistani population and the frequency increases with increasing age and stroke was more prevalent in men than in women.It shows that subdural hematomas were more prevalent out of hemorrhagic strokes than other subtypes of extraaxial type of hemorrhagic strokes.Complications like odema of cerebral tissues, midline shift and disabilities were more common in hemorrhagic strokes than in infarctive strokes. Also the cases of stroke due to rupture of a blood vessel presented earlier to hospital because of early onset of symptoms as compared to cases of stroke due to blockade of a blood vessel.

\section{INTRODUCTION:}

Stroke is one of the leading causes of death not only in developed as well as in underdeveloped countries of the world.. The frequency of stroke due to blockage of vessel,rupture of a blood vessel and its subtypesand their respective causes also varies in different regions of the world. For example in Pakistan, stoke prevalence study conducted on adult pashtun community residing in Karachi reported a prevalence of $4.8 \%$ which was alike in men and women. This was the highest ever reported prevalence of stroke in world.
Computed tomography (CT) is a non-invasive diagnostic imaging procedure that uses a combination of $x$-rays and computed technology to produce horizontal and axial images called slices of the body. A CT-scan shows images of any part of the body which are more detailed than standard x-rays.

CT has played a great role in diagnosis of

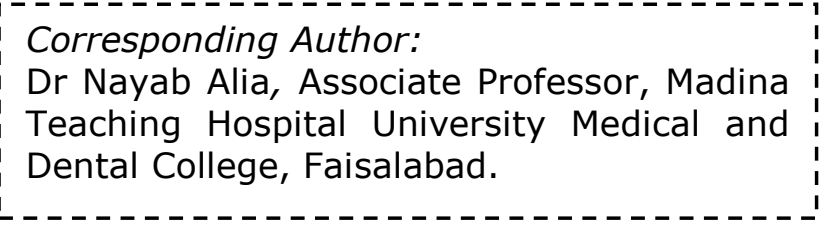


patients who present with an acute neurological deficit and the head CT-scan now plays an integral role in the screening and treatment of stroke patients.CT-scan without giving contrast medium is the first line investigation in patients having suspicion of stroke and due to its unique sensitivity for the detection of blood. There are three possible classes of CT-diagnosis when a patient presents with an acute neurological deficit. It can be non-ischemic stroke that is further subdivided as hemorrhagic or nonhemorrhagic. Hemorrhagic stroke can be of different types like subdural, epidural, subarachnoid or intracerebral hemorrhagic. Non-hemorrhagic stroke includes stroke due to ischemia, tumors or infections of brain.

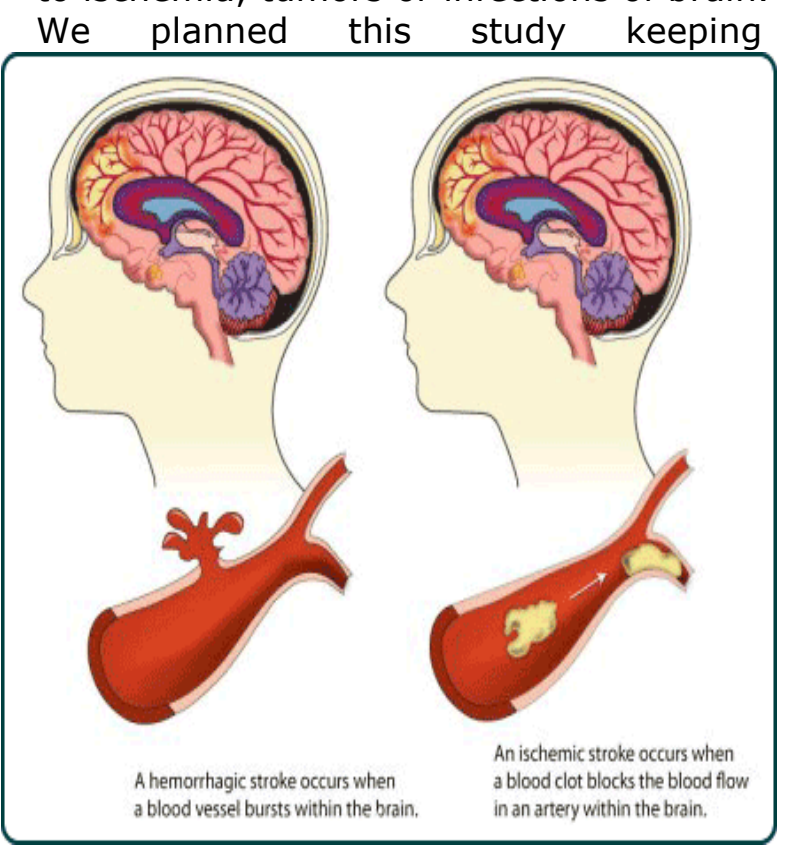

consideration the paucity of available data in Pakistan regarding the stroke patients.

\section{OBJECTIVES:}

The purpose of the study was to assess relative frequencies of different types and subtypes of stroke in Pakistani population using CT and to correlate CT findings with duration of onset of symptoms, risk factors and outcome of stroke.

\section{MATERIAL AND METHODS:}

A prospective study with convenient sampling technique was undertaken in LAHORE by cross sectional study design. 100 adult, accessible cases were included from SOCIAL SECURITY HOSPITAL MULTAN ROAD LAHORE, during the period of nine months after approval from hospital authorized research comitee.

A questionnaire was designed to extract relevant clinical data from the patients. It will record age, sex, stroke type, duration of onset of symptoms, location of lesion, surrounding edema, midline shift, predisposing factors and in some cases time of death. Equipment used in Social Security Hospital Multan Road Lahore is 64 slice Toshiba CT unit. Informed and written permission was taken either from the patients or relatives. The CT brain was performed with following protocol. Noncontrast enhanced trans-axial CT of the brain with slice thickness of $4 \mathrm{~mm}$ contiguous slices was performed. Patient's data was recorded and analyzed with the help Microsoft Excel and SPSS 20.

\section{INCLUSION CRITERIA:}

Only those who had complete information and meeting the world health organization criteria for the clinical diagnosis of stroke will be finally included in study.

\section{EXCLUSION CRITERIA:}

Patients of stroke secondary to tumors and abscess (infections of brain), pediatric group (age 1-14 Years), those secondary to trauma and with incomplete documentation and investigations will be excluded from my study. The two major events that cause brain damage in stroke are blockage or rupture of a blood vessel. Ischemic stroke that is the blockage of a blood vessel which is about 80 \%of all strokes.In this type, decreased or absent circulating blood because of a thrombus or an embolus deprives neurons of necessary substrates. The affects of blockage are fairly rapid because the brain does not store glucose which is the chief energy substrate and thus is incapable of anaerobic metabolism. Non traumatic intracranial rupture of a blood vessel represents about $10 \%$ to $15 \%$ of all strokes and it originates from deep penetrating vessels.it could cause injury to brain tissue by disrupting connecting pathways and causing localized pressure injuries. Destructive biochemical substances 
released play an important role in tissue destruction in either case.

Ischemic stroke is the lack of sufficient blood flow to supply cerebral tissue due to narrowed or blocked arteries either the main arteries supplying the brain or arteries entering the brain. Ischemic strokes could be broadly subdivided into thrombotic and embolic strokes. Atherosclerosis is the main reason of narrowing of blood vessels. The occurrence of fatty plaques lining the blood vessels is also a major factor and as the plaques grow in size, the blood vessels become narrowed and the blood flow to the area beyond is reduced. The areas of an atherosclerotic plaques that are damaged could cause a blood clot to form which blocks the blood vessel causing a thrombotic stroke. blood clots or debris from elsewhere in the body, typically the heart valves could travel through the circulatory system and block narrower blood vessels in embolic strokes and based on etiology of ischemic stroke, a more accurate sub classification is generally used;

Large vessel disease; refers to atherosclerosis of large vessels including the internal carotid artery, vertebral artery, basilar artery and other main branches of circle of willis.

Small vessel disease:refers to changes due to chronic disease such as diabetes,hypertension, hyperlipidemias and smoking that lead to decreased lumen of the arterial walls or narrowing and occlusion of lumen of smaller vessels-collateral circulation: the impact of brain damage due to blockade of a blood vessel is greatly impacted by the presence of collaterals in the affected area of brain and a good collateral circulation could be associated with a better outcome.

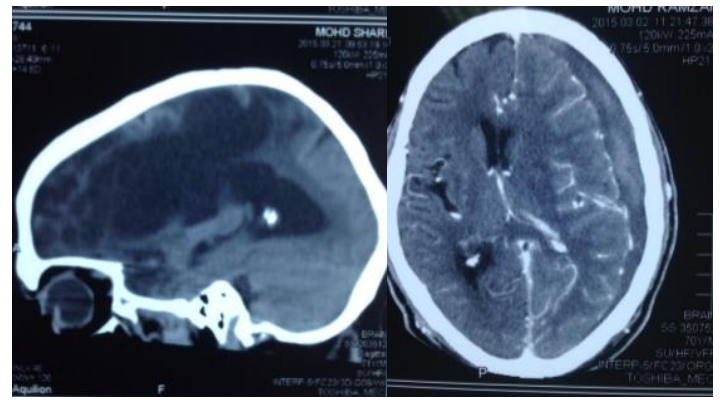

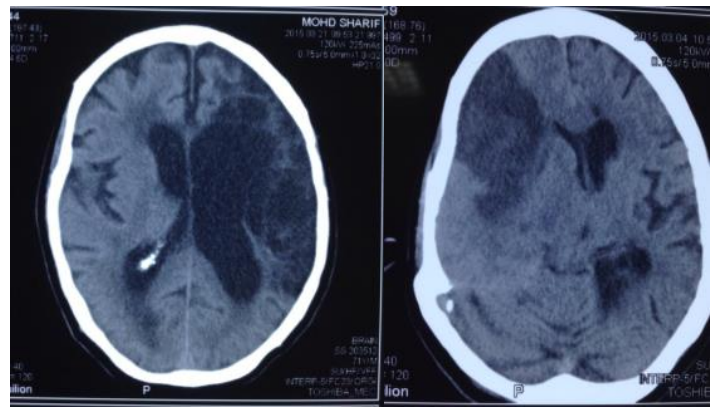

\section{RESULTS:}

shows total hundred patients were observed from October 2014 to June 2015 with mean \pm standard deviation was $61.16+14.13$.It shows that 100 cases that are taken, containing both males and females, $54 \%$ cases are males that suffered from stroke and $46 \%$ are females that suffered from some kind of stroke. Results shows that out of hundred stroke cases taken in study, $82 \%$ got infarctive stroke and $18 \%$ got hemorrhagic stroke.It shows that out of hundred cases studied, $18 \%$ cases are suffered from hemorrhagic stroke and out of $18 \%$ cases $7 \%$ cases got subdural hemorrhage while $11 \%$ suffered from some other subtype of hemorrhagic stroke.It shows that out of $18 \%$ hemorrhagic stroke cases, $2 \%$ suffered from epidural hemorrhagic stroke while $16 \%$ suffered from some other subtype of hemorrhagic stroke. Another result shows that out of $18 \%$ hemorrhagic stroke cases, $2 \%$ suffered from subarachnoid hemorrhage. It shows that out of $18 \%$ hemorrhagic stroke cases, $7 \%$ suffered from intracerebral hemorrhage.It shows that out of $18 \%$ hemorrhagic stroke cases, 7 got surrounding edema around hemorrhage while $11 \%$ did not got any surrounding odema.besides, $5 \%$ infarctive stroke cases also got surrounding odema and $77 \%$ cases do not got. It also shows that out of $18 \%$ hemorrhagic stroke cases, $13 \%$ cases got midline shift as well while $5 \%$ cases do not got.besides, out of infarctive stroke cases $5 \%$ also got midline shift while $76 \%$ do not got it .Results shows that among $18 \%$ hemorrhagic stroke cases. 


\section{Hemorrhagic "Death Outcome Crosstabulation"}

\begin{tabular}{|c|c|c|c|c|c|c|c|c|c|}
\hline & & Out $C$ & ome & & & & & & \\
\hline & 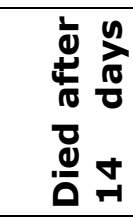 & 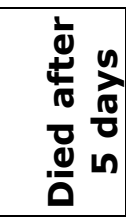 & 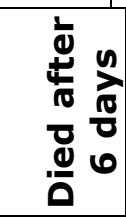 & 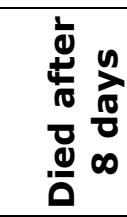 & 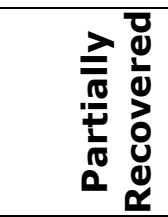 & 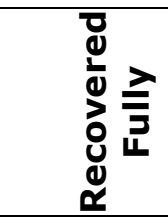 & 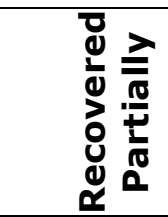 & 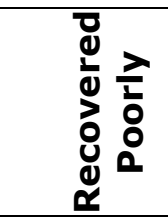 & 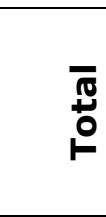 \\
\hline \multirow{3}{*}{$\begin{array}{l}\text { Hemorrh } \\
\text { agic } \\
\text { Yes } \\
\text { No }\end{array}$} & 1 & 0 & 1 & 2 & 0 & 38 & 25 & 15 & 82 \\
\hline & 0 & 3 & 0 & 1 & 0 & 5 & 5 & 4 & 18 \\
\hline & 1 & 3 & 1 & 3 & 0 & 43 & 30 & 19 & 100 \\
\hline
\end{tabular}

Stroke Type "Duration of onset of Symptoms (in days) Cross tabulation"

\begin{tabular}{|c|c|c|c|c|c|c|c|c|c|c|c|c|}
\hline & \multicolumn{9}{|c|}{ Duration of onset of Symptoms (in days) } & \multirow[t]{2}{*}{ Total } \\
\hline & & & $\stackrel{\mathscr{\Xi}}{\mathrm{C}}$ & $\stackrel{0}{3}$ & 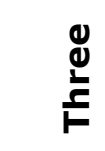 & $\begin{array}{l}\text { 호 } \\
\text { 운 }\end{array}$ & $\sum_{i \frac{1}{4}}^{0}$ & $\frac{x}{n}$ & ญ & 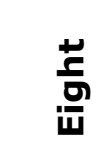 & 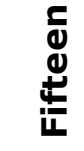 & \\
\hline \multirow{4}{*}{ 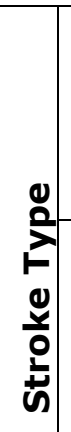 } & \multirow{4}{*}{ 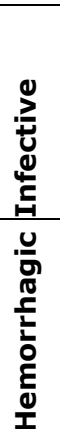 } & 007 & 15 & 19 & 8 & 16 & 10 & 7 & 4 & 2 & 1 & 82 \\
\hline & & $\begin{array}{l}\% \\
\text { within } \\
\text { Stroke } \\
\text { Type }\end{array}$ & $\begin{array}{l}18.3 \\
\%\end{array}$ & $\begin{array}{l}23.2 \\
\%\end{array}$ & $\begin{array}{l}9.8 \\
\%\end{array}$ & $\begin{array}{l}19.5 \\
\%\end{array}$ & $12.2 \%$ & $8.5 \%$ & $\begin{array}{l}4.9 \\
\%\end{array}$ & $\begin{array}{l}2.4 \\
\%\end{array}$ & $\begin{array}{l}1.2 \\
\%\end{array}$ & $\begin{array}{l}100.0 \\
\%\end{array}$ \\
\hline & & Count & 8 & 8 & 1 & 1 & 0 & 0 & 0 & 0 & 0 & 18 \\
\hline & & $\begin{array}{l}\% \\
\text { within } \\
\text { Stroke } \\
\text { Type }\end{array}$ & $\begin{array}{l}44.4 \\
\%\end{array}$ & $\begin{array}{l}44.4 \\
\%\end{array}$ & $\begin{array}{l}5.6 \\
\%\end{array}$ & $5.6 \%$ & $0.0 \%$ & $0.0 \%$ & $\begin{array}{l}0.0 \\
\%\end{array}$ & $\begin{array}{l}0.0 \\
\%\end{array}$ & $\begin{array}{l}0.0 \\
\%\end{array}$ & $\begin{array}{l}100.0 \\
\%\end{array}$ \\
\hline \multirow{2}{*}{\multicolumn{2}{|c|}{ Total }} & Count & 23 & 27 & 9 & 17 & 10 & 7 & 4 & 2 & 1 & 100 \\
\hline & & $\begin{array}{l}\% \\
\text { within } \\
\text { Stroke } \\
\text { Type }\end{array}$ & $\begin{array}{l}23.0 \\
\%\end{array}$ & $\begin{array}{l}27.0 \\
\%\end{array}$ & $\begin{array}{l}9.0 \\
\%\end{array}$ & $\begin{array}{l}17.0 \\
\%\end{array}$ & $10.0 \%$ & $7.0 \%$ & $\begin{array}{l}4.0 \\
\%\end{array}$ & $\begin{array}{l}2.0 \\
\%\end{array}$ & $\begin{array}{l}1.0 \\
\%\end{array}$ & $\begin{array}{l}100.0 \\
\%\end{array}$ \\
\hline
\end{tabular}

\section{DISCUSSION:}

The purpose of this study is to establish frequency of stroke and its different subtypes in Pakistani population. For this purpose a prospective study with convenient sampling technique was performed.100 stroke cases from Nawaz Sharif Social Security Hospital, Multan road Lahore were taken over the period of nine months starting from October 2014 to June 21015.Patients with age group less than 14 years, and stroke cases 
secondary to trauma, brain infections and tumors were excluded from this study.

The results of this study showed that that stroke is more prevalent in males than in females. Out of hundred stroke cases, $54 \%$ were male and $46 \%$ were females. Another such study was performed on the West Europe that shows that incidence of stroke is $33 \%$ higher in males than in females. The result I got from this study is that incidence of infective stroke is greater as compared to hemorrhagic stroke like out of hundred stroke cases $82 \%$ are of infective stroke and $18 \%$ were diagnosed to have hemorrhagic stroke. Another such study was performed in Belluno Province Italy over a period of one year. Over this one year they got 474 cases of stroke out of which 319 are of infective strokes and 93 were suffered from hemorrhagic stroke.

Another study was conducted in Denmark in 2001 on a sample size of 39484 patients.The patients underwent an evaluation including stroke severity, CT, and cardiovascular risk factors. They were followed up from admission until recovery or death. Factors involving ischemic stroke than hemorrhagic stroke were diabetes, atrialfibrillation, previous myocardial infarction etc. Hemorhagic stroke was associated with an overall higher mortality risk. The increased risk was however time dependent.Initially risk was 4 fold, after 1 week it was 2.5 fold, after 3 weeks it was 1.5 fold, and after 3 months stroke type did not correlate to mortality. Similar results were found in my studies that patients suffering from haemorhagic stroke, more number of patients died at day 5 and less number of patients died after 1 week.

\section{LIMITATIONS:}

Some of the patients of infective stroke involving larger areas of brain get hemorrhagic transformation after few days that worsens their prognosis.

Many of the patients of hemorrhagic stroke presents late to hospitals because of illiterate background and lack of travelling facilities from peripheral areas inspite of developing symptoms earlier than infective stroke cases.

\section{CONCLUSIONS:}

The conclusion of my study is that prevalage of infective stroke is higher over hemorrhagic stroke and incidence is more in males than in females. This frequency increases with advancing age and Hypertension is a major risk factor in stroke cases. Also mortality and morbidity is higher in hemorrhagic stroke cases because of development of odema, midline shift and brain herniation and they present early as compared to infective stroke cases because of early development of symptoms.

\section{REFRENCES:}

1. Hopkins J, CT or CAT scan of the brain. 1992.92 (3): 07650

2. Hines $H$, The internet stroke center. Department of neurology.

3. 1998-1999 92(3): 1192-1198

4. Hanna D, Human brain anatomy in computerized images:303

5. Taylor T, anatomy and physiology instructor. 1999-2015

6. Pelizzari,Charles A, Chen,etal, Journal of computer assisted tomography. Lippincott raven publishers.13(1):2

7. Levin $D N$, The brain integrated three dimensional display of MR and PET images. TSNA.1989.172(3):10

8. Hopkins J, computed tomography (CT or CAT) scans of the brain. Health library.1992.92(3) 07650:1192-1198

9. Osuntokun $B B$, Akinkugbe $O B$, incidence of stroke in African city. Radiology journal, 1973-1975. 1979(10):205-207
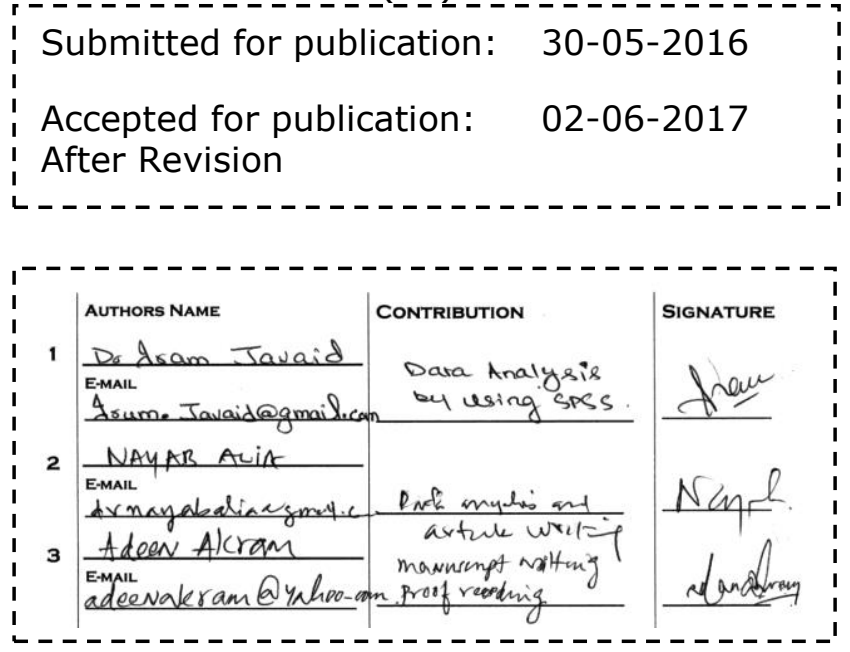